THURSDAY, DECEMBER 26, 1878

\section{THE ASSOCIATION OF LOCAL SOCIETIES}

T OCAL Societies: What is their aim and what pur1 pose do they serve? How may this aim be most surely gained? How can this purpose be most effectively carried out? These are questions which naturally arise when considering the subject of local societies.

The aim of every local society should be to raise the intellectual status of the locality. The purpose to do so in that way most generally useful. It is the mind of the community which has to be raised by affecting the minds of the individuals. Individual minds are to be affected by contact with material surroundings. These surroundings influence us through the powers of observation, hence careful and accurate observation must exist among the members of a society fulfilling its proper functions. The greater the number of members exercising such observation the greater the usefulness of the society. It is almost needless to instance other mental qualities as necessary for success, because experience shows that when once the observing faculty has received its due share of attention, the power of using the observations made follows in due course. The faculty of observation must be drawn out and cultivated by contact with matter in relation to man, and by contact with matter considered apart from man as existing in a state of nature. And just as it is important that in the culture of the individual a one-sidedness should be specially avoided, so in raising the culture of a community it is equally important that opportunities or suggestions for mental improvement all round should be afforded. Hence we are inclined to think it advisable that especially in the case of small country towns scientific studies, or suggestions for such, should proceed from the same platform as those studies which are often spoken of as more purely literary. Of course literature includes the records of science, but still for general purposes the meaning is clear when a literary institute or society is spoken of as distinguished from a scientific. Among the lower types of animals there is a want of specialisation of parts; very different functions may be performed by the same part or the whole of the body; in the higher, specialisation prevails, each function has its own organ, and the function is performed more efficiently. In large towns science may be pursued apart from general literature, and even each special science may stand on its own platform, but in small towns this is out of the question, and I believe unadvisable, for the over-performance of one function in the lowly organised society $\mathrm{s}$ checked by the claim of the general body. Moreover, the tastes of a community being naturally various, it becomes essential to present intellectual food of various kinds. Hence we cannot but think that small local societies should be both literary and scientific. The two aspects of culture will support and strengthen each other, and the introduction of a new clique, or party, or sect be avoided. For it must be remembered that one of the distinct collateral advantages of such societies is that a common platform is provided upon which men of all political or religious beliefs can stand and work together. No one who is acquainted with the social conditions of our small towns can underrate the importance of this.

$$
\text { VOL, Xix.-No. } 478
$$

But how are such societies to work? I would reply, from within, outwards. Not, in the first place, by calling in extraneous belp, by engaging eminent men to give courses of lectures, but by arousing the spirit of inquiry and observation amongst the townsfolk. Let but a few natives come forward with short papers on any subjects with which they may be especially acquainted, the subjects being treated in such a way as to elicit a discussion or inquiries, a spirit of interest will soon be aroused, and minds put into a proper attitude for the reception of truths before quite unknown to them, and for the prosecution of some special subject as a study. In practice I would strongly advise the following course to be pursued by any embryo literary and scientific society. Have two classes of meetings : one the ordinary meeting, at which members alone (and therefore townsfolk) should read short papers, upon which a discussion should afterwards be encouraged; and public lectures, given mainly by nonresidents, and to which the general public should be admitted on the payment of a small fee. At the ordinary meeting the local talent and observation is drawn out, and at the public lecture new subjects are introduced to the notice of members. At the former, notices of local phenomena and history, or the occasional original investigations of members, are recorded; at the latter, new lines of thought are often indicated, or systematic instruction given in some one subject.

A society established on some such basis is then in a position to encourage the collection of objects of locat natural history, to establish a local museum, and carry out field excursions during the summer months. Moreover, the experience of many years past has shown me that the life-and therefore the growth of culture-in such a society is far greater than in those cases where only a yearly course of lectures is organised, the greater part of them being given by strangers. Next comes the oft-repeated question, But how long will such a society last? Many are ready to say, We have tried some such plan, and success has attended our efforts for one or two years, and then the society has died out. On this part of the subject a few words will now be said, and the remarks made are founded upon experience gleaned amidst the practical working of local societies in Cumberland during the past nine years.

How, then, can permanence be ensured? In a small town or district local resources and talent are apt to become exhausted or unavailable. A time will surely come when the intellectual movement will wane and the society be on the brink of non-existence. But the very usefulness of such a movement must consist in its stability; there should be a growth, not a bare existence. To insure this stability I suggested some years ago that the four societies then existing in the Lake District and West Cumberland should be united for general purposes, while each society should retain its individuality. After many preliminary difficulties were overcome, the union was effected, and since that time each society has grown stronger, four new societies have been formed, and the total number of members increased from a few hundred to nearly $\mathrm{I}, 200$.

The objects to be attained by this association of societies are as follows:- 1 . Increased strength to be cerived from mutual help, encouragement, and a spirit of 
honest emulation. 2. The union affords greater facilities towards publishing transactions and securing the services of eminent lecturers. 3. An annual meeting of the associated societies affords an opportunity for the discussion of principles of working and promotes the general life. 4. The annual meeting being held in a fresh town each year helps to keep the country alive to the Association work, and encourages the formation of new societies.

The constitution of the Cumberland Association is as follows:-The president to be a man of local note and high culture, and to serve for a period not greater than two years.' The Presidents of individual societies to be vice-presidents of the Association. The council of the Association to consist of two delegates from each society, chosen annually. The treasurer and secretary (honorary) to be one and the same person, and fully acquainted with the county in all its aspects.

The working of the Association is carried on thus: The Association secretary keeps a record of all papers and lectures brought before the individual societies. Before the commencement of each winter session he communicates with all the local secretaries, and from his knowledge of available intellectual stores in the county, helps each in the drawing up of the winter programme in whatever direction help may be specially needed. It is his duty also to help forward the establishment of local classes where such are possible. At a council meeting held in the autumn some public lecturer is decided upon who shall go the round of the associated societies during the winter, and a grant is made towards his expenses from the Association funds (of which more anon), the rest being made up by each society served.

The annual meeting takes place at Easter or in May, and lasts two or three days. The Association President delivers his annual address, reports from the several societies are read and discussed, original papers are read, lectures given by one or more eminent men, and field cxcursions made.

At the close of each winter session the local secretaries send into the Association secretary any papers which have been selected by the local committees as worthy of publication. If the Association council approve these papers they are published in the Transactions at the Association expense. The funds of the Association are gathered thus: Each society pays an annual capitation grant of $6 d$. per head on all its members. There is also a class of Association members, residing at a distance from, and not belonging to, any local society, who pay an annual subscription of $5 s$., and are virtually considered members of all the societies, and have the privileges of such. The Transactions are sold to the societies and Association members at the price of $\mathrm{r} s$., the public being charged $2 s$. $6 d$. Some of the societies purchase copies to the full number of their members, and present them, others take only a limited number of copies (determined by the local society committee) and re-sell to those of their members who care to possess them. In this way the greater part of an edition of 800 copies of the Annual Transacions is disposed of. Authors are allowed extra copies of their own papers at a moderate charge, and when all expenses are met, a fair balance is left to carry on to the next year.

It should be noted that of the eight societies in Cum-

- $x$ The Lord Bishop of Carlisle acted as president for two yenrs, and I. Flctcher, M.P. F.R.S., is now in hes second year of presidency. berland, now associated, the local annual subscriptions of members in each society is generally $5 \mathrm{~s}$.; in one case, however, it is $3 s .6 d$, and in another $2 s .6 d$. It is a rule of the Association that members going from one society to another to afford help in the carrying out of the various programmes, should have their expenses paid by the society helped. Such is the general constitution and mode of working of the Cumberland Association, which has undoubtedly succeeded in its aim, so far as the keeping up of existing societies and the formation of new ones is concerned. The Annual Transactions, too, include many papers of local value, and some of general interest, while among the eminent men who have kindly come forward to lend their services at the Annual Meetings, are the Astronomer-Royal, the Bishop of Carlisle, Prof. Shairp, Prof. Wm. Knight, and I. Fletcher, M.P., F.R.S. At present, however, the Association is but in its infancy, and may be considered more or less of an experiment, yet that some such method of union is desirable amongst lozal societies in the various counties or districts of England few will deny. Time will show how the system may be im. proved and varied to suit special circumstances, but I cannot but think that the plan of association to carry out the larger objects of societies, and the annual meeting of the associated societies in successive towns of a county, must economise labour and promote the healthy culture of the county in which the work is carried on.

Amongst the difficulties presenting themselves in the early days of the association, the following occurred. For several previous years a Cumberland and Westmoreland Antiquarian and Archæological Society had flourished, and it was feared that the new County Association would clash with its existence. The Antiquarians thought it best not to amalgamate with the associated society, its constitution being in many points different from theirs, but it was resolved that whenever papers, bearing on local antiquarian or archæological subjects were read before any of the associated societies, these papers should be offered by the Association council to the Antiquarian and Archæological Society for publication in their Transactions if deemed worthy. Moreover, some of the officers of the Association are active members of the Archæological Society, and so far from their being any antagonism, the two decidedly belp one another forward in the general work of gleaning local knowledge and diffusing culture.

As hon. secretary of the Cumberland Association, I should feel very grateful for any hints or suggestions from the readers of NATURE. What is wanted in every county is more culture, and that carried on in a natural way, and with a true love of nature in all her aspects.

\section{J. CLIFTON WARD}

\section{NEWCOMB'S LUNAR RESEARCHES}

Researches on the Motion of the Moon, made at ihe United States Nawal Observatory, Waslington. By Simon Newcomb, Professor U.S. Navy. Part I. (Washington, 1878 .)

THE author prefaces his work with the remark that for several years after the publication of Hansen's Tables of the Moon, there was a very general belief that 